\title{
REFLEXÕES SOBRE AS CONSTRUÇÕES IDENTITÁRIAS DE DOCENTES DE EDUCAÇÃO À DISTÂNCIA A PARTIR DA ANÁLISE LINGUÍSTICO DISCURSIVA DE INTERAÇÕES NO GÊNERO CONSÍGNIA
}

\author{
REFLECTIONS ON THE IDENTITY CONSTRUCTIONS OF E-LEARNING \\ TEACHERS THROUGH THE TEXTUAL GENRE CONSIGNA
}

\author{
Lilian Soares de Figueiredo Luz' \\ Rita de Cássia Souto Maiori
}

RESUMO: Acompanhando mudanças na sociedade, a modalidade de ensino à distância surge reestruturando uma série de ações interacionais, o que também implica numa reconstrução identitária (HALL, 2004; CORACINI, 2003, 2005; CELANI; MAGALHẪES, 2002) do/a professor/a. Baseadas na perspectiva da Linguística Aplicada (MOITA LOPES, 2002, 2006) e sob o viés da abordagem qualitativa de pesquisa (TRIVIÑOS, 1987; LÜDKE; ANDRÉ, 1986) e do estudo de caso (YIN, 2005), temos o objetivo de refletir interpretativamente sobre as identidades, através das atuações linguístico discursivas dos/as docentes no gênero consígnia, no ambiente virtual Moodle na Educação a Distância. Observamos, com o estudo, que esse gênero, organizado com saudações e orientações, sinaliza para a construção de diferentes relações sociais entre docente-discentes e que essas diferenças revelam fragmentações identitárias próprias da busca de uma reavaliação ético-discursiva (SOUTO MAIOR, 2009, 2018) das práticas que 0 ambiente demanda para os/as profissionais.

PALAVRAS-CHAVE: Gênero consígnia. Educação à distância. Identidade docente

ABSTRACT: Following the changes in society, the modality of e-learning arises by restructuring a series of interactional actions (HALL, 2004; CORACINI, 2003, 2005; CELANI; MAGALHÃES, 2002. Based on the perspective of Applied Linguistics (MOITA LOPES, 2002, 2006) the qualitative research (TRIVIÑOS, 1987; LÜDKE; ANDRÉ, 1986) and also in case study (YIN, 2005), it had the purpose of thinking interpretatively about identities through of the linguistic-discursive teachers practices of the genre consigna present in the virtual environment Moodle, points to the construction of different social relations between teacher-students reveal identity fragments specific to the search for an ethical-discursive reappraisal of the practices (SOUTO MAIOR, 2009, 2018) that the platform demands for the professionals.

KEYWORDS: Genre consigna. E-learning. Teacher's identity.

Submetido em: 31 jan. 2018 Aprovado em: 14 ago. 2018

\footnotetext{
i Professora de ensino médio do Instituto Federal de Alagoas (IFAL) e do curso de Especialização em Linguagens e Práticas Sociais (IFAL-Murici). E-mail: liliansfluz@hotmail.com.

ii Professora da Graduação em Letras e do Programa de Pós-Graduação em Letras e Linguística da Universidade Federal de Alagoas (UFAL). E-mail: ritasoutomaior@gmail.com.
} 


\section{Introdução}

A temática identidade vem sendo bastante discutida na atualidade e, talvez, ainda mais por estarmos vivenciando uma época de estreitamentos das relações entre os povos, o que provoca, por um lado, diálogos entre tradições diferentes - muitas vezes, com a tentativa de construção de 'verdades' únicas e universais -, e, por outro lado, a busca constante de referências identitárias que notabilizem as diferenças como algo criativo que diferencia positivamente os aspectos de um povo.

Influenciadas, principalmente, pelo fenômeno da globalização, essas diferentes reações estão atreladas, obviamente, ao contexto cada vez mais digitalizado da sociedade que, por sua vez, promove certas quebras de fronteiras entre tempo-espaço e, consequentemente, mudanças nas estruturas sociais, éticas, políticas e culturais. Essas estruturas que se encontravam antes alicerçadas na noção de estabilidade, hoje, são problematizadas por um processo de constantes mudanças que apontam para uma sociedade fluida e instável (BAUMAN, 2001) ou fragmentada e deslocável (HALL, 2004). O que essas visões têm em comum é a certeza de uma força motriz que desestabiliza e estabiliza, ao mesmo tempo, construtos identitários, principalmente, ao assumir o estado de vigília de "novos eus", a partir de identificações na pluralidade.

Além disso, consideramos, como dissemos acima, que as mudanças na aproximação entre os povos vêm gerando discussões sobre valores e verdades instituídas, e, nesse sentido, promovendo também afastamentos, recondicionando, talvez por isso mesmo, "outras" identidades de gênero, de nacionalidade, de etnias, etc ${ }^{1}$.

Nesse vasto campo de discussões, alguns aspectos podem ser focalizados, a depender do campo teórico-metodológico em que nos situamos, para fins de aprofundamento e/ou desnaturalizações. Os interesses vão desde os estudos mais gerais sobre as relações sociais entre os sujeitos até a análise

\footnotetext{
1 Estamos chamando "outras" para evitar novas por entender que essas não surgem como novidade, pois entendemos que são apenas instituídas como "diferente de antes". Elas não surgem, tomam para si certo status quo.
} 
dos momentos de identificações que possibilitam a análise da eticidade discursiva (SOUTO MAIOR, 2018) que compõe a construção das identidades e de novas possibilidades identitárias no cenário contemporâneo (cf. CORACINI, 2000, 2003; MOITA LOPES, 2002; FABRÍCIO; MOITA LOPES, 2002; CELANI; MAGALHÃES, 2002, dentre outros).

No campo da Linguística Aplicada, assumindo a constituição do sujeito pelo movimento de estabilidade e desestabilidade de sentidos a partir das relações dialógicas que constituem esse movimento, de uma maneira modesta, debruçamo-nos sobre essa última temática, considerando que as transformações da sociedade/sentido também provocam a instituição de novos construtos/sujeitos que estão relacionados a essas transformações, encontrando-se, por isso mesmo, atrelados a possíveis conotações e implicações ideológicas ${ }^{2}$ de compreensão mais geral de mundo.

Observaremos, mais especificamente, aqueles sujeitos que assumem determinados papéis sociais e que respondem ao cenário do ensino e aprendizagem, o da profissão docente, entendendo que esse profissional tem, como um dos objetivos de sua profissão, formar cidadãos inseridos no contexto social (MARCELO, 2009). Nesse sentido, educação "é processo de humanização e tem a finalidade de inserir os sujeitos como partícipes nas relações sociais." (SOUTO MAIOR, 2018, p. 147).

Tendo as reflexões sobre a identidade como um dos elementos fundamentais deste estudo e justificadas pela necessidade de dirimir a distância muitas vezes observada e denunciada entre pesquisa e ação efetiva na escola, entendemos que esse interesse nos impulsiona a repensar o sistema educacional e a formação dos profissionais que nele atuam (CELANI; MAGALHÃES, 2002). Nosso interesse, mais especificamente, é pelo profissional que trabalha com o ensino a distância, o que consideramos ser um papel que requer da profissão além de um repensar sobre as relações interacionais instituídas entre tradição e as demandas que subjazem as práticas mais digitais

\footnotetext{
2 Ideológico no sentido de referir-se às áreas da atividade intelectual humana e de sempre expressar uma posição valorativa, excluindo assim o sentido negativo, restrito, de "mascaramento do real" (VOLÓCHINOV, 2014).
} 
da contemporaneidade ${ }^{3}$, um repensar sobre os discursos que a subjazem e a notabilizam.

Temos o objetivo, portanto, de refletir sobre a questão da identidade do/a docente da Educação a Distância (doravante EAD), a partir do que ele/a registra no seu discurso em consígnias. Entendemos que, por se tratar de uma modalidade de ensino em que há uma separação de espaço e tempo ${ }^{4}$, as práticas linguístico-discursivas apresentadas no ambiente EaD são indícios importantes para a reflexão sobre a identidade docente, porque é a "palavra que constitui justamente o produto de interação do locutor e do ouvinte" (VOLÓCHINOV, 2014, p. 117) e essa ação ética-reflexiva de pesquisa pode auxiliar no entendimento de demais fatores ligados ao processo de ensino e aprendizagem 5 .

Já que "é na tentativa de rearticular a relação entre sujeito e práticas discursivas que a questão da identidade [...] volta a aparecer." (HALL, 2004, p. 105), para compreender a construção da identidade do professor de EaD, analisamos o processo de interação entre professor/a e aluno/a, numa perspectiva dialógico-ética proporcionada pelos gêneros discursivos do ambiente virtual.

Nesse espaço, onde encontramos textos que são escritos com objetivo de nortear o trabalho desenvolvido, é de fundamental importância observar como os discursos vão refletindo e refratando (VOLÓCHINOV, 2014) dizeres que reiteram ou deslocam papéis dos sujeitos que ali se encontram. Esse encontro social possui determinados padrões interativos, próprios dos gêneros presentes no ambiente, mas também pode nos revelar a transitoriedade das mudanças de papéis e de ações tão próprias dessa situação histórica cultural de fluidez em que nos encontramos (BAUMAN, 2013).

\footnotetext{
${ }^{3}$ Não estamos discutindo teoricamente sobre as mudanças das últimas décadas, mas apenas destacamos que as práticas que chamamos digitais trazem reformulações nas práticas sociais. ${ }^{4}$ Sendo assim, consideramos as mudanças da concepção de espaço, segundo Bauman (2001), quando esse diz que o espaço "perdeu sua qualidade restrita e é facilmente transposto tanto na sua versão 'real' como na versão 'virtual', a modalidade de ensino a distância surgiu e, com ela, surgiu uma série de transformações na identidade docente, que até então certo momento histórico era considerado "senhor de suas ações" (cf. GERALDI, 2003).

${ }^{5}$ Reconhece-se a importância de considerar que o que se constrói em pesquisas sobre práticas da linguagem não está à parte do social e que a interrelação entre os campos se revela pela responsabilidade do sujeito no mundo (BAKHTIN; VOLOCHINOV, 2004), porque só dessa maneira a atividade é ato. (SOUTO MAIOR, 2013, p. 34).
} 
Consideramos, portanto, que refletir sobre esse material que muitas vezes apresenta uma disciplina ou simplesmente informa sobre determinada ação dentro do ambiente é uma maneira de refletir sobre as constituições identitárias e as características das mudanças que vêm se instituindo nas relações sociais, principalmente, naquelas que afetam a interação professor/a e aluno/a.

Dentre os textos no ambiente, entendemos que as consígnias ${ }^{6}$ podem ser um excelente lócus de observação de como o/a professor/a se institui identitariamente, pois é com esse gênero que o/a docente estabelece o "tom" de suas aulas, já que os discursos que são encontrados através dessas produções estabelecem negociações entre professor/a e aluno/a e dizem respeito ao estabelecimento de uma relação identitária em que não só os papéis mais esperados são ratificados, mas outras características de identidade podem ser apresentadas e aceitas, ou não, pelos/as interlocutores/as. Por isso, escolhemos o gênero consígnia como elemento para a focalização no estudo. Como supracitado, esse funciona como a "voz" do/a professor/a, na modalidade escrita da língua, se considerarmos, analogicamente, que ele/a tem seu paralelo na própria voz do/a professor/a em sala de aula, na interação face a face na modalidade do ensino presencial. Ambos, a nosso ver, têm como objetivos a orientação de atividades, organização do espaço, acolhimento dos/as alunos/as, estabelecimento de normas de convivências, entre outros.

As práticas linguístico-discursivas apresentadas nesse gênero, características do ambiente virtual de aprendizagem do sistema Moodle (plataforma de aprendizagem a distância baseada em um software livre), permitem-nos refletir sobre a identidade desse/a docente, além de possibilitar a análise de quais características na atuação com esse gênero podem permitir

\footnotetext{
${ }^{6}$ Esse termo é usado com frequência na educação a distância. Há poucos registros de estudos sobre conceito e características desse termo. O texto "O mistério da consígnia", da autora Cristiane Zuan Esteves, publicado no blog http://lumeopovoempe.wordpress.com/2011/08/29/omisterio-da-consignia/ foi o estudo mais significativo do ponto de vista da origem e definição. Segundo a autora, essa palavra é de origem francesa e significa ordem, instrução, "orientações ou pressupostos sobre determinado assunto ou atividade que devem ser seguidos para sua correta execução". O interessante é que o termo é bastante usado em textos pedagógicos e teatrais, porém sem nenhum estudo mais aprofundado sobre esse gênero. $\mathrm{Na} \mathrm{EaD}$, a consígnia pode ser conceituada como um texto injuntivo (MARCUSCHI, 2008) porque pode ser usada para apresentar encaminhamentos das atividades propostas pelo professor, no entanto, ele pode servir também de uma ponte para estabelecer um diálogo com os alunos nas aberturas das semanas, demonstrando seu caráter misto.
} 
uma maior interação, aspecto fundamental no processo de ensino-aprendizagem dessa modalidade de ensino. Diante dessas características, a necessidade de se refletir sobre a questão da identidade do/a professor/a da $\mathrm{EaD}$ se torna evidente e esse é o objetivo deste artigo, como já dissemos acima.

Para essas discussões, além de produzirmos, inicialmente, um breve panorama sobre a educação a distância, também construímos uma referência sobre conceitos de identidade e discurso, focalizando, em seguida, características da identidade docente, mais especificamente a partir da análise interpretativa de dados. Para fins de análise, foram utilizados dois recortes de consígnias das disciplinas Linguística Aplicada e Leitura e Produção de Textos, do curso de Letras, oferecido pelo Instituto Federal de Alagoas (IFAL), através do sistema de Universidade Aberta do Brasil (UAB) ${ }^{7}$.

Adiante, apresentaremos um breve esboço de como a EAD se institui como espaço de ensino.

\section{Navegando pela educação da Educação à Distância}

A Educação a Distância (EaD) é uma modalidade de ensino em que professores/as e alunos/as, na maior parte do tempo, estão separados fisicamente no espaço e/ou pelo tempo, e utilizam, de forma intensiva, as Tecnologias de Informação/Comunicação (TIC). Essa modalidade vem sendo cada vez mais utilizada na educação básica, na educação superior e em cursos abertos, entre outros, pois possibilita o acesso a um grande número de informações e à interação entre pessoas distantes geograficamente e de diferentes contextos ${ }^{8}$.

Nas últimas décadas, a EaD passou por grandes modificações, tanto do ponto de vista estrutural quanto do perfil dos professores/as e alunos/as que a utilizam (BELLONI, 2008). Segundo Belloni (2008), essas grandes modificações

\footnotetext{
${ }^{7}$ Cursos ofertados em 2014.

${ }^{8}$ Para ilustrar o crescimento do acesso a essa modalidade, apresentamos os dados da pesquisa de 2014 da Associação Brasileira de Estágios (ABRES) que mostra, entre os anos de 2012 e 2013, o avanço de $3,6 \%$ de matrículas nos cursos superiores a distância e 3,85\% nos presenciais. Assim, os cursos de $\mathrm{EaD}$ já representam mais de $16,2 \%$ do total de matriculados em graduação. Dos 1.153.572 alunos matriculados em EaD, 999.019 estudam em instituição de ensino privada e 154.553 em instituição pública.
} 
se deram em três gerações: a primeira, caracterizada pelo estudo por correspondência e influenciada pelo modelo fordista e neofordista; a segunda, impulsionada pela utilização de novas tecnologias que possibilitaram um tratamento mais individualizado; e, a terceira, a tendência contemporânea, que utiliza a internet para proporcionar um aprendizado mais interativo e autônomo.

Essa evolução da EaD, que começou com um ensino por correspondência até chegar a uma modalidade de ensino, nos dias atuais, que visa à interação e que apresenta mais de um instrumento para interlocução, evidencia também a necessidade de essa forma de educação se adequar a diferentes maneiras interlocutivas, que vão desde questionamentos de como posso interagir discursivamente com o outro, a partir dos diversos objetivos das práticas de ensino, até a interdependência das escolhas de gêneros que trabalho na prática vivenciada nas atividades. Algumas das características da pós-modernidade também trazem implicações, de certa forma, a cada um desses âmbitos de atuação como veremos adiante. Segundo Giddens (1991, p. 69, grifos do autor), por exemplo, a

estrutura conceitual do distanciamento tempo-espaço dirige nossa atenção às complexas relações entre envolvimentos locais (circunstâncias de co-presença) e interação através de distância (as conexões de presença e ausência).

Esse autor considera que, na era moderna, o nível de distanciamento tempo-espaço aumenta consideravelmente e que é maior do que qualquer período precedente, tornando "alongadas" as relações entre formas sociais e eventos locais e distantes. Ainda segundo Giddens (1991), a globalização enreda ainda mais as diferentes regiões e contextos sociais neste processo de alongamento. Dessa forma, consideramos que isso pode revelar, na prática do ensino a distância, a negociação das relações a partir de diferentes matizes que podem ir desde uma postura mais formalizante e tradicional, até uma postura menos tradicional e menos distanciada. $O$ encontro entre o que pratico com a ajuda dos elementos paralinguísticos em situações de ensino presencial - como entonação de voz, gestos, sorrisos etc - e o que posso ou devo praticar no ensino a distância (em que não tenho esse suporte contextual dos elementos paralinguísticos, mas posso desenvolver estratégias de registro), expõem 
características que vão dialogar com crenças e valores ético-discursivos de: "como deve agir um/uma professor/a para que..." e "como deve agir um/a aluno/a para que....".

Como podemos observar com as discussões acima, as mudanças ocorridas na modalidade a distância nos faz refletir sobre problemáticas que já rondavam o ensino presencial, mas que também se diferenciam por serem próprias dessa transformação de modalidade.

Para acompanhar essa transformação, o Governo Federal regulamentou o artigo 80 da Lei n 9.394, de 20 de dezembro de 1996, que trata das diretrizes e bases da educação nacional, através do decreto $n^{0} 5.622$, de dezembro de 2005, conforme expomos abaixo:

\begin{abstract}
Art. 1 - Para os fins deste decreto, caracteriza-se a educação a distância como modalidade educacional na qual a mediação didáticopedagógica nos processos de ensino e aprendizagem ocorre com a utilização de meios e tecnologias de informação e comunicação, com estudantes desenvolvendo atividades educativas em lugares ou tempos diversos. (BRASIL,2005).
\end{abstract}

A partir desse parâmetro, percebemos que Educação a Distância vem em um processo de crescimento no Brasil. Entendemos que esse crescimento se deve, em parte, à necessidade de se ter uma qualificação profissional e a uma política de expansão educacional para acompanhar uma sociedade pósmoderna que exige do indivíduo um desenvolvimento de uma série de competências como autonomia, flexibilidade, cooperativismo, entre outras. Essa modalidade, nesse ínterim, se torna uma boa opção para a qualificação profissional por ser um sistema que possibilita uma educação de forma virtual para lugares de difícil acesso, onde não há universidades, por exemplo.

Entendemos que, muitas vezes, não são encontradas situações ideais da implementação desse sistema de ensino (falta de espaço para a organização dos cursos, problemas com a distribuição de energia ou sinal de internet, falta de laboratórios equipados etc.) e também fica posto que, nesse sistema, em tese, o/a aluno/a não precisa deixar o trabalho para estudar, além de ter a liberdade de fazer o seu horário de estudo ${ }^{9}$.

\footnotetext{
9 'Na prática, compreendemos que, a depender das condições de trabalho, mesmo essa modalidade se mostra inviável, o que nos impulsiona a considerar que ainda precisamos avançar
} 
Por sua vez, é visível a necessidade de se desenvolver uma educação a distância voltada para o desenvolvimento de processos de ensino-aprendizagem que acompanhem a sociedade contemporânea e globalizada, apresentando, principalmente, um projeto de ensino que possa de fato responder ao mesmo tempo à qualidade almejada no ensino e à produção de uma formação que vise ao desenvolvimento da criticidade e emancipação humanas. As propostas de ensino, portanto, podem se debruçar sobre os significados de mundo estruturados nas práticas interacionais, nos textos trabalhados, nas atividades empreendidas e problematizar os sentidos depositados nesses espaços, considerando uma perspectiva ética dos discursos. (SOUTO MAIOR, 2018, p. 155)

É interessante para nós destacar neste momento de nossas reflexões que as características do contexto contemporâneo, de toda forma, transformaram o público EaD. Esse, a nosso ver, se tornou bastante diversificado e essa diversidade vem provocando, paralelamente, mudanças na concepção das relações de ensino, o que afeta sobremaneira as apresentações identitárias do/a professor/a dessa modalidade que busca, muitas vezes, atender a alguns princípios básicos da EaD que, segundo Belloni (2008, p. 33), são: "aprendizagem autodirigida, disponibilidade de meios e materiais, programação da aprendizagem e interatividade entre estudantes e agentes de ensino".

A interatividade nessa modalidade, citada por Belloni (op. Cit.), mostra-se peculiar por ser, na maioria das vezes, assíncrona e por dispensar a presença física do/a professor/a, na maior parte do processo. Todavia requer do/a agente de ensino a autorrepresentação constante de um papel. Em outras palavras, ele/a dá a matiz de sua aula a partir da apresentação do que significa a disciplina, quais suas demandas, o que deve ser feito e como tudo deve ser concluído, tudo isso permeado pela relação que constrói a partir da linguagem.

Os indícios discursivos da construção dessa relação são parte fundamental na apresentação, acompanhamento e finalização da disciplina. Os papéis construídos, a partir da linguagem empregada, e a aceitação ou não das

muito na implementação de uma política de trabalho que inclua a obrigatoriedade de uma formação continuada de qualidade, prevista na ação do trabalho, com carga horária prevista e paga. 
identidades, ali postas, são elementos que fazem parte do processo de ensino/aprendizagem e podem estimular (ou não) o sucesso do aproveitamento dos objetivos do curso ou da disciplina.

Dizendo quem ele/a é para o/a aluno/a e qual o/a aluno/a que ele/a quer para sua disciplina, o/a professor/a vai delegando posições que podem ser afirmadas ou deslocadas, pelo processo de interlocução que vai se instituindo no curso ou disciplina com o outro. Essa negociação formaliza certa individualização de papéis e se dá como característica de uma sociedade moderna de ampliação da participação social e política dos sujeitos (GIDDENS, 1991). Essa fluidez ou instabilidade de posições e papéis, muitas vezes provocada pelos efeitos do sentido de globalização, também é apresentada por Bauman (2001), quando esse diz que

A sociedade moderna existe em sua atividade incessante de 'individualização', assim como as atividades dos indivíduos consistem na reformulação e renegociação diária da rede de entrelaçamentos chamada 'sociedade'. (BAUMAN, 2001, p. 39).

Como uma das atuações dessa reformulação diária das atividades dos sujeitos, podemos entender que, no campo das relações digitais, a identidade contemporânea dialoga com determinadas "ações esperadas" ou "padrões sociais interacionais instituídos". ${ }^{10}$ Mais especificamente, no campo do ensino a distância, esse diálogo pode ocorrer através do que é entendido por Giddens (1991, p. 133), como uma busca de adaptação ao perfil de risco da contemporaneidade. O que seria, a nosso ver, um xeque-mate permanente nas ações de avaliação do como proceder em sala de aula, dos discursos elaborados naquele espaço, das iniciativas empreendidas nas atividades desenvolvidas pelo grupo, nesse diálogo entre ações/discursos esperados e ações/discursos construídos. Essa identidade em movimento e, por isso, não fixa, estabelece constante avaliação de como posso ou devo proceder nas interações ali estabelecidas.

\footnotetext{
${ }^{10}$ Segundo Coracini (2003, p. 97), é essa "perspectiva de um mundo fragmentado, que questiona valores tradicionais, os centros que apagam as margens e anulam as diferenças, que se tem denominado pós-modernidade ou modernidade tardia."
} 
Observaremos, em seguida, como a identidade do sujeito situado na contemporaneidade se caracteriza, num contexto mais geral, para, logo após, frisarmos os aspectos referentes à identidade profissional docente nessa reflexão sobre ação esperada e ação instituída.

\section{Identidade docente na Educação à Distância}

Para desenvolvermos a reflexão sobre a identidade docente na Educação a Distancia, é importante inicialmente compreendermos que noção de identidade, de um modo geral, sofre certas transformações ao longo do tempo. Alguns autores, como Hall (2006) e Coracini (2005) ${ }^{11}$, só para citar alguns, apesar de apresentarem essas transformações de maneiras diferentes, grosso modo, entendem que o termo adquire certa conotação mais complexificada a partir do século $X X$.

Hall (2006, p. 13), a partir do processo histórico por que passaram as concepções de identidade, pensa os sujeitos como: a) sujeito centrado de razão, concepção bem individualista; b) sujeito sociológico, esse "refletia a crescente complexidade do mundo moderno e a consciência de que este núcleo interior do sujeito não era autônomo e auto-suficiente", mas era formado na relação com "outras pessoas importantes para ele", que mediavam para o sujeito os valores, sentidos e símbolos - a cultura - do mundo que ele/ela habitava; c) sujeito pósmoderno que é conceituado "como não tendo uma identidade fixa, essencial ou permanente".

Para ele, as sociedades do final do século XX sofreram uma mudança estrutural que se irradiava nas transformações das "paisagens culturais", antes sólidas e estáveis, como o gênero, a sexualidade, a etnia, a raça e a nacionalidade para menos sólidas e instáveis.

\footnotetext{
11 Considerando a identidade num processo histórico, basicamente, encontramos três acepções desse sujeito: aquelas de antes e imediatamente depois do iluminismo, somadas a que se encontra contextualizada na pós-modernidade ou contemporaneidade. Temos, no sujeito do lluminismo, um ser centrado em eixos bem firmados e homogêneos, respaldados pela razão onisciente que se sobrepunha à concepção da Idade Média que colocava Deus como centro do mundo (CORACINI, 2000). Nessa visão antropocêntrica (homem visto como indivíduo capaz de pensar e tomar para si os objetos do mundo como apreensão das verdades por ele instituídas), a construção da identidade é uma descrição de características fixas.
} 
Mais contemporaneamente e a partir da segunda metade do século $X X, 0$ sujeito é entendido como não tendo uma identidade fixa, pois essa identidade se torna uma "celebração móvel", transformada continuamente em relação às formas pelas quais somos representados ou interpelados nos sistemas culturais que nos rodeiam (HALL, 2006). Essas transformações, segundo o autor, influenciam a formação cultural das pessoas que acabam ficando divididas periodicamente entre os velhos e novos padrões, bem como entre as mais variadas classes que surgem na metade do século.

Diante do cenário de transformações da nossa contemporaneidade, a educação a distância teve que se reelaborar numa sociedade globalizada que apresenta questionamentos sobre identidade e que, segundo Bauman (1998, p. 155), resulta.

principalmente da dificuldade de se manter fiel a qualquer identidade por muito tempo, da virtual impossibilidade de achar uma forma de expressão da identidade que tenha boa probabilidade de reconhecimento vitalício, e a resultante necessidade de não adotar nenhuma identidade com excessiva firmeza, a fim de poder abandonála de uma hora para outra, se for preciso.

A impossibilidade de reconhecimento vitalício de um papel central para o/a professor/a em relação ao seu papel em sala de aula, a sua relação com o/a aluno/a e a forma como deve/pode dialogar demanda a necessidade de reflexão sobre as implicações ético-discursivas dos encontros identitários dessas relações.

Também é importante destacar que a própria definição do papel do/a docente dessa modalidade que, na maioria das vezes, não atua apenas a distância, já se estrutura como híbrida. Desse modo, o/a professor/a que pertencia e/ou ainda pertence ao ensino presencial, e também exerce a sua docência na EaD, parece buscar se adequar a uma modalidade que é dinâmica, por estar numa constante atualização, para que a barreira tempo-espaço dessa modalidade seja transposta através dos recursos tecnológicos e pedagógicos de que dispõe, apontando, assim, para uma formulação identitária híbrida e fluída.

E é obvio que, ao considerar essas características, as identidades assumidas muitas vezes se fundam nas ações que ali são encontradas e funcionam como indícios das interlocuções ali estabelecidas, principalmente, 
porque as interações entre professor/a-aluno/a são mediadas pelas práticas discursivas do ambiente, intermediadas pelas significações identitárias.

Como as identidades são construídas através, do/pelo/no discurso, no interior das práticas sociais (HALL, 2004), o aspecto de transição e instabilidade deve ser levado em conta, já que participamos de uma sociedade e somos também influenciados por ela. De qualquer forma, essa construção identitária, por sua dinâmica de reestruturação, também se faz instável.

Desse modo, a constituição de uma identidade docente poderia vir a se confundir com papéis sociais porque estariam atrelados a significações sociais da profissão ou a discursos institucionalizados da profissão, pois, segundo Pimenta (2012, p. 20), a identidade profissional "se constrói, pois, a partir da significação social da profissão; da revisão constante dos significados sociais da profissão; da revisão das tradições." E é nesse sentido de reformulação que Pimenta aponta em seu discurso a necessidade de entendermos que os papéis dialogam com as identificações mais subjetivas, digamos assim.

Se nos referirmos à identidade do professor/a em EaD, podemos observar que essa identidade se constrói a partir da significação social dessa profissão numa época em que a tecnologia está em evidência, da revisão das fronteiras entre a modalidade presencial (representante das tradições) e a modalidade a distância (caracterizada pelo aspecto emergente e virtual). Também pode ser construída através do significado que cada docente concede à sua prática docente a partir de suas crenças e valores que se fundam identitariamente nas práticas discursivas que assumem e em relação com os interactantes do contexto. Nesse sentido, Moita Lopes (2002, p.62) entende que "ao considerarmos as identidades sociais de nossos interlocutores ao nos engajarmos no discurso, estamos simultaneamente (re-) construindo as nossas."

Castells (2010), por sua vez, diferencia papéis de identidade, entendendo que papéis são definidos por normas estruturadas pelas instituições e organizações de sociedade, e identidade, ainda segundo esse autor, são, de alguma forma, as identificações que operam como reconhecimento pelo próprio sujeito. Esse pesquisador exemplifica papéis dizendo que alguém pode ser, ao mesmo tempo, trabalhador, mãe, vizinho, militante socialista, sindicalista, jogador de basquete, frequentador de uma determinada igreja e fumante. Por 
outro lado, como dissemos, para ele, identidades constituem fontes de significado para os próprios atores. No entanto, Castells reconhece que as identidades podem se relacionar com papéis, da mesma forma como entendemos que as identificações podem se relacionar com as identidades aparentemente mais sólidas.

Não diferente desse aspecto instável, se encontra a identidade docente, ou nas palavras de Castells (op. cit), há uma relação entre o papel docente e a construção da identidade de sujeitos que a assume como representantes do papel, pois a profissão do/a professor/a está relacionada ao contexto ou momento histórico a partir de uma resposta à construção social, como exposto anteriormente.

Dessa forma, o caráter dinâmico dessa profissão deve-se ao fato de ser o resultado de práticas sociais. Sendo assim, consideramos que todos esses aspectos são refletidos e refratados (VOLÓCHINOV, 2014) nos discursos construídos por esse profissional em sua prática docente, já que todo discurso "resulta de um consenso entre indivíduos socialmente organizados no decorrer de um processo de interação" (VOLÓCHINOV, 2014, p.45). Por isso, a importância de se analisarem as práticas linguístico-discursivas do ambiente virtual de aprendizagem para se refletir sobre a construção dessa identidade docente na EaD.

Assim, entendemos por identidade o processo de construção de significado múltiplo, fonte de tensão e contradição "tanto na autorrepresentação quanto na ação social” (CASTELLS, 2010, p.22).

Destacamos, neste sentido, parafraseando Santos (2010, p. 314) ao discutir sobre a trajetória do colonialismo visando ao lugar da solidariedade, que uma nova política de identidade e de diferença pressupõe um novo paradigma epistemológico e que, de fato, só nessa trajetória será possível reconhecer "as diferenças e distinguir, entre elas, as que inferiorizam e as que não inferiorizam, na específica constelação social de desigualdades e de exclusões em que elas existem." (SANTOS, 2010, p. 314).

Nesse estudo, consideramos que o questionamento sobre a identidade docente EaD está atrelado principalmente à preocupação em compreender quais são os espaços de identificação preenchidos com a atividade a distância desse 
docente e quais as implicações desses preenchimentos discursivos em relação à constituição de sua identidade.

Assim, é possível entender que as constantes mudanças no cenário econômico, político e social, marcadas pelo fenômeno da globalização, provocam diversas reflexões sobre a identidade de vários segmentos dessa sociedade chamada de pós-moderna, já que, na pós-modernidade, há uma data de validade para os conhecimentos o que obriga, de certa forma, os profissionais a ingressarem em uma constante atividade de formação e aprendizagem (MARCELO, 2009). Nesse sentido e nessa relação entre formação, conhecimento e docência, é que refletiremos agora sobre a identidade do professor/a e a construção do objeto de ensino.

\subsection{Identidade docente e a construção do objeto de ensino}

A relação entre o/a docente e a construção do objeto de ensino nos revela características fundamentais da identidade que esse/a professor/a vem construindo ao longo do tempo. Associamos aqui ao objeto de ensino, comumente entendido como conteúdo, todo conjunto dos elementos que constituem o saber explicitamente "ensinado" e o que implicitamente o subtende, como, por exemplo, padrões interacionais, expectativas interlocutivas, gêneros educacionais, modalidades de ensino.

Segundo Geraldi (2003), de um período compreendido até início da modernidade - momento em que o/a professor era o/a produtor/a do conhecimento e aquele/a que ensinava não se diferenciava daquele/a que produzia o saber -, aos primórdios do mercantilismo - período em que esse mestre se constitui com outra identidade, pois o que ensina transmite um saber já produzido -, temos uma modificação significativa de identidade docente em relação ao objeto de ensino já que desloca o/a professor/a da condição de produtor/a a transmissor/a do saber.

Já do mercantilismo ao capitalismo contemporâneo, ainda segundo Geraldi (2003, p. 92), alteram-se "profundamente as condições de produção de bens e com estas alterações, novas divisões do trabalho." Essas alterações de condições de produção do saber geram, de acordo o autor, outra relação entre 
atividade de produção de conhecimentos e a atividade de ensino que se relaciona com o que ele chama de "parafernália didática" que é "posto à disposição do trabalho de transmissão." (GERALDI, 2003, p. 93). Esse autor considera que se, na etapa anterior, era da responsabilidade dessa identidade docente articular eixos epistemológicos e as necessidades didáticopedagógicas, "no mundo tecnologizado, muda-se qualitativamente a identidade e o trabalho do professor" (GERALDI, 2003, p. 93).

Seguindo essas reflexões, a identidade docente na EaD é alvo de discussões por se tratar de uma modalidade de ensino que tem como base a separação espaço-temporal entre docente e discente, a utilização das tecnologias de informação e comunicação (TIC) para superar essa separação, a inscrição de um sujeito que registra assincronicamente sua identidade no ambiente (seja por escrito, por divulgação de imagens ou por meio de vídeos e/ou áudios) e a preocupação constante na produção de uma resposta a esses registros.

Considerando que vivenciamos os discursos através de textos que, por sua vez, nos são apresentados através de gêneros, elegemos as consígnias ${ }^{12}$ como foco de estudo dos elementos que fazem parte do coletivo que constitui o objeto de ensino. A consígnia, gênero discursivo híbrido que se estabelece na construção do objeto de ensino como uma forma de diálogo entre o/a professor/a e o/a aluno/a, pode nos apresentar indícios identitários através das práticas linguístico-discursivas de que dispõe esse gênero, já que "a palavra está sempre carregada de um conteúdo ou de um sentido ideológico ou vivencial." (VOLÓCHINOV, 2014, p. 99).

\footnotetext{
${ }^{12}$ Consígnias são os enunciados de abertura e acompanhamento das atividades das disciplinas no ambiente moodle. Observamos uma ausência de trabalhos que abordam esses enunciados, chamados de consígnias, pelos profissionais dos cursos de graduação inseridos no sistema UAB promovidos pelo Instituto Federal de Alagoas (IFAL). E, a partir das observações de uma das autoras deste artigo como revisora de textos dos cursos de Letras e Biologia (UAB/IFAL), foi possível perceber que esses textos consistem um gênero discursivo híbrido que deve ter um destaque na produção do ambiente de uma disciplina, já que também é uma forma de diálogo entre o professor e o aluno, contribuindo assim para o processo de ensino-aprendizagem.
} 


\title{
30 gênero consígnia e o Ambiente Virtual de Aprendizagem
}

Para essas reflexões sobre identidade nessa modalidade de ensino, utilizamos a concepção de Volóchinov (2014) sobre a linguagem como processo ou forma de interação entre sujeitos. Observa-se que Volóchinov (2014, p.85) aponta que os fenômenos do discurso são definidos por suas orientações dialógicas e que há diferentes formas e graus dessas orientações, o que chamamos aqui de perspectiva ética do discurso ${ }^{13}$. Segundo ele, a "atmosfera social do discurso que envolve o objeto faz brilhar as facetas de sua imagem". (VOLÓCHINOV, 2014, p.85). Essas orientações ideológicas, vivenciadas na linguagem em uso, dão-se por meio dos gêneros. Nesse sentido, a noção de gênero está relacionada às situações de interação dentro de uma determinada esfera social e, no estudo em questão, da esfera da educação a distância. Segundo Rodrigues (2005), a esfera educacional e suas condições específicas (relações sociais entre os participantes de uma interação e desenvolvimento tecnológico) constituem o gênero discursivo na interação verbal. Para ratificar esse aspecto, citamos as palavras de Volóchinov:

\begin{abstract}
A atividade mental do sujeito constitui, da mesma forma que a exterior, um território social. Em consequência, todo o itinerário que leva da atividade mental (o "conteúdo a exprimir") à sua objetivação externa ("a enunciação") situa-se completamente em território social. Quando a atividade mental se realiza sob a forma de uma enunciação, a orientação social à qual ela se submete adquire maior complexidade graças à exigência de adaptação ao contexto social imediato do ato de fala, e, acima de tudo, aos interlocutores concretos. (VOLÓCHINOV, 2014, p. 121-122).
\end{abstract}

A Partir do entendimento da complexidade do ato enunciativo, exposta na citação acima, compreendemos também que o gênero consígnia é extremamente propício para a reelaboração de papeis em sala de aula, e que refletir sobre a construção da identidade docente é essencial para compreender

\footnotetext{
${ }^{13}$ A perspectiva ético-discursiva corresponde a fios ideológicos que compõem os enunciados e resulta na construção de sistemas operacionais de sentido. Esses sistemas sustentam as relações entre sujeitos, os sentidos compartilhados, a formulação da compreensão do mundo etc. Trata-se, logo, de uma instâncias discursiva crítica visto que contextualiza o dito, buscando o resgate da compreensão situada e sensível. Esse resgate ou arquitetônica se dá pela contextualização de sentidos, considerando quem diz, para quem (explicitamente e implicitamente), como diz etc.
} 
esses papeis, já que "a palavra, como fenômeno ideológico por excelência, está em evolução constante, reflete fielmente todas as mudanças e alterações sociais" (VOLÓCHINOV, 2014, p.202).

Acompanhando as constantes transformações ocorridas na nossa sociedade pós-moderna, em especial, as mudanças do modelo de educação e, aqui, reportando para a modalidade a distância, podemos considerar as consígnias (enunciados de abertura da disciplina ou das atividades propostas pelo/a professor/a no ambiente virtual de aprendizagem) inicialmente como um gênero de tipologia mista, por ter a possibilidade de apresentar várias dimensões tipológicas, por exemplo, uma consígnia de uma atividade proposta pode ter uma, duas ou mais dimensões, como uma sequência injuntiva, uma descritiva e outra expositiva, já outra pode ter apenas uma sequência injuntiva e descritiva. Em segundo lugar, a dimensão dialogal está presente em quase todas as consígnias, através das saudações e despedidas, como uma forma de o/a professor/a estabelecer uma interação com o seu interlocutor/a/, que é seu/sua aluno/a.

A presença do caráter dissertativo se dá quando o/a dicente coloca conceitos e aspectos da disciplina ou de temas trabalhados durante as semanas. O gênero instrucional também é percebido quando o/a professor/a apresenta instruções de estudo ou das atividades elencadas para serem cumpridas pelos/as alunos/as. Há ainda o caráter descritivo da ação do/a professor/a para a disciplina, ao apresentar estratégias e metodologias que serão utilizadas por ele/a para contribuir com o processo de aprendizagem do/a aluno/a.

Assim, o gênero consígnia na modalidade de ensino a distância apresenta-se com seu caráter híbrido, ao ser construído por características de outros gêneros e tipologias textuais, como a carta ou bilhete, os textos instrucionais, dissertativos etc., numa tentativa de, a partir do discurso, estabelecer uma relação dialógica entre professor/a e aluno/a, num ambiente virtual onde os sujeitos desse processo estão separados fisicamente, porém unidos através de ferramentas virtuais utilizadas para superar a barreira espaçotemporal em que se encontram. Abaixo, prosseguiremos com as análises. 


\section{Análise das construções identitárias e das estratégias do dizer}

Dentro de uma perspectiva qualitativa de pesquisa (TRIVIÑOS, 1987; LÜDKE \& ANDRÉ, 1986), numa abordagem de estudo de caso (YIN, 2005) do contexto situacional, coletamos os dados para essa pesquisa no ambiente virtual de aprendizagem (AVA) do Moodle do curso de Letras, oferecido pelo Instituto Federal de Alagoas (IFAL), do sistema da Universidade Aberta do Brasil (UAB), no ano de 2014. Nosso objetivo, como dito anteriormente, foi o de refletir sobre a identidade docente em EaD, através da análise das práticas linguísticodiscursivas do gênero consígnia. Para tal, os movimentos ético-discursivos foram depreendidos e interpretados.

Foram utilizados dois recortes de consígnias de um professor e de uma professora $^{14}$ do curso de Letras (UAB/IFAL). O primeiro recorte refere-se à abertura da disciplina Linguística Aplicada e servirá para exemplificar esse caráter híbrido do gênero em questão, conforme discutido acima, além também de servir de base para uma reflexão sobre a identidade da professora Ingrid e as implicações ético-discursivas dessa identidade. Já o segundo recorte, o da consígnia de abertura da 5ª semana da disciplina Leitura e Produção de Textos, consubstanciará as discussões sobre a identidade docente em questão e as implicações ético-discursivas do ato enunciativo. A seguir, daremos prosseguimento à análise

\subsection{Os "papéis" e as identidades}

Abaixo, reproduzimos a consígnia de abertura da disciplina Linguística Aplicada, escrita pela professora Ingrid. Essa turma apresentava 48 alunos/as matriculados/as e foi ministrada nos meses fevereiro e março de 2014.

\footnotetext{
${ }^{14}$ Utilizamos nomes fictícios para preservar a identidade dos/as envolvidos/as na pesquisa.
} 


\section{Trecho 1:}

Neste início da disciplina, apresentaremos alguns textos básicos para as nossas leituras e atividades. Mostraremos uma visão panorâmica de vários conceitos de Linguística Aplicada e faremos paralelos ou contrastes dessas concepções de acordo com vários pesquisadores dessa área de estudo.

No trecho 1, a utilização da $1^{1}$ pessoa do plural, nos verbos das ações elencadas por ela, pode ser entendida como uma forma: a) de evitar o tom individualista, por se apresentar como fala coletiva; b) de se criar uma proximidade com o/a aluno/a. Porém essa aproximação ainda se fundamenta numa certa formalidade, já que o emprego pode ser considerado também como o plural majestático ${ }^{15}$.

Já no parágrafo seguinte, sua expectativa é de colaboração na ação, uma vez que a discussão e a reflexão, segundo suas orientações, devem ser feitas pelo/a discente. Dessa forma, ela vai instituindo papéis para ela e para eles/as. A professora vai apresentar, mostrar e fazer paralelos ou contrastes, esperando, com essas ações, que os discentes discutam e reflitam.

\section{Trecho 2:}

Esperamos, dessa forma, discutir e refletir sobre os assuntos relacionados à disciplina durante todo o curso. Para isso, é muito importante que as leituras sejam feitas.

Ao começar o parágrafo com o verbo "Esperamos" (dessa vez não pressupondo de fato o coletivo, pois quem espera de fato é a docente), seguido da expressão coesiva "dessa forma", referindo-se às atividades e ações ditas no parágrafo anterior, relacionadas com os objetivos "discutir" e "refletir", a professora novamente mostra a relevância da disciplina, com mais um traço dissertativo no texto.

Ela finaliza o parágrafo com um pedido/orientação aos alunos: "Para isso, é muito importante que as leituras sejam feitas", característica da sequência tipológica injuntiva. Mesmo não utilizando o verbo no imperativo, percebemos

15 O plural majestático, convertido em plural de modéstia, ainda é muito usado, como recurso estilístico, tanto na comunicação formal como na literatura, por oradores e escritores, como forma de evitar o tom individualista no discurso, quando este se apresenta como fala coletiva, ou para criar proximidade com o leitor. 
que há a intenção de sugerir um procedimento: fazer as leituras indicadas pela professora.

Interpretamos, do que foi apresentado, novamente, uma constituição identitária estabelecida pela ratificação discursivo-ético de certo distanciamento, pois, ao invés de dizer: "... é muito importante que você faça as leituras", ela utiliza a voz passiva sem o agente "... que as leituras sejam feitas".

A voz instituída é de ações a serem feitas (por ela e pelos/as discentes), num roteiro institucional próprio de papéis estabelecidos pela escola numa perspectiva mais tradicional ${ }^{16}$.

A partir desse trecho, além do caráter híbrido do gênero consígnia, podemos observar traços da identidade da professora, através da construção do seu discurso. Desse modo, é possível perceber que há utilização da linguagem formal, talvez fundamentada pelo que ela representa do lugar que ocupa como professora. A professora Ingrid também cita nomes representativos da linguística. Esses aspectos, de certa forma, a academiciza, já que o ambiente é de um curso de licenciatura.

Assim, as práticas linguístico-discursivas apresentadas nesse gênero nos permitem refletir sobre a identidade dessa professora, além de analisar quais características dessa profissional possibilitam a interação, aspecto fundamental no processo de ensino-aprendizagem dessa modalidade de ensino, pois, segundo Volóchinov (2014), é através da palavra que nos definimos em relação ao outro. Ainda segundo o autor:

isto é, em última análise, em relação à coletividade. A palavra é uma espécie de ponte lançada entre mim e os outros. Se ela se apoia em mim numa extremidade, na outra apoia-se sobre meu interlocutor. (VOLÓCHINOV, 2014, p. 117).

A seguir, apresentamos uma discussão sobre as práticas linguísticodiscursivas, o discurso ético e as constituições da identidade.

\footnotetext{
${ }^{16}$ Entendemos tradicional como práticas fundamentadas em características da modernidade, de papéis identitários sólidos, papéis configurados a partir de relações de poder esperados na manutenção da lógica de reprodução de mercado.
} 
De acordo com as ferramentas e o ambiente em que são utilizadas, as consígnias podem ter várias funções: fazer a abertura da disciplina e das semanas, apresentar as instruções para as atividades propostas, mostrar a relevância dos textos e materiais complementares, promover a interação entre professor/a e aluno/a, possibilitando uma construção colaborativa de conhecimentos. Selecionamos, para esse segundo momento, um recorte da consígnia de abertura da 5a semana da disciplina Leitura e Produção de Texto para apresentar aos/ às alunos/as quais leituras e procedimentos da semana auxiliariam no processo de ensino-aprendizagem. Vejamos o recorte:

Figura 2 - Ambiente virtual da disciplina Leitura e Produção de Textos

+14 junho $2014-20$ junho 2014 ,

Pessoal de São José da Laje, um BOM DIA com o eco e resplendor das serras, neblinas e vegetação dessa região aí!!! rsrsrsrsss!!!

Olhe, aqui, nas atividades sobre o conto: "Temas sociais no conto"; "Estrutura narrativa do conto"; e "Produzindo um conto" - vocês precisam se identificar, senão, não teremos como saber quem produziu essas atividades, a fim de colocarmos as notas e comentarmos...

Para enviar as atividades use a ferramenta: "Tarefa". Quando abrir, clique no "link": "Acrescentar item", ok?

Abraços carinhosos e tenham BONS DIAS!!!

Damião Augusto, Denise e Andrea

Queridos alunos!!! Bom dia!!!

Estamos iniciando a nossa $5^{a}$ semana de aula...

o que faremos?

1. Uma leitura de material teórico dos elementos da estrutura narrativa do conto, enquanto gênero textual ou discursivo da narrativa ficcional.

Em seguida, discutiremos sobre questốes sócio-político-filosóficas abordadas pelos autores no conto que você escolheu para trabalhar.

Depois, faremos um estudo dos elementos constitutivos da estrutura narrativa do conto que escolheu para trabalhar.

$\widehat{E}$, finalmente, entraremos na producão de um conto para montagem de uma brochura éconcorrêncía num concurso de contos.

Vamos à luta!!! Bom trabalho para todos nós!!!

Lucas, Tutor 1 e Tutor 2
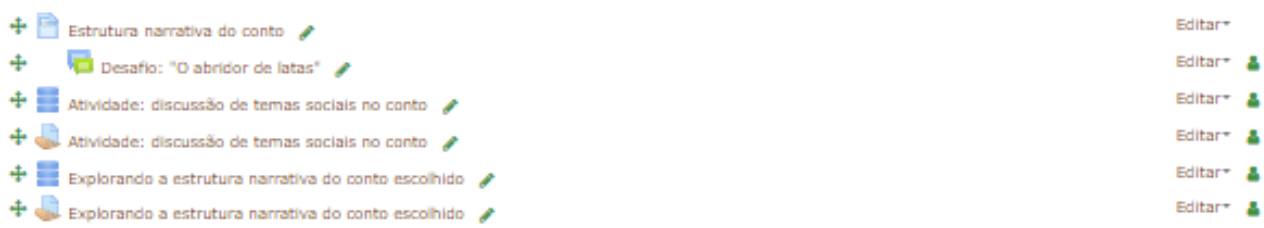

Fonte: Plataforma Moodle do curso de Letras - UAB/IFAL, 2014.

Nessa consígnia de abertura da semana, podemos observar a separação em dois momentos por uma linha pontilhada. A ordem desses trechos, porém, não apresenta a sequência dos momentos de postagem, já que o Moodle pode 
seguir uma sequência de postagem e a consígnia mais recente poderá ficar acima da anterior. Assim, pressupomos que a primeira consígnia que se inicia com "Pessoal de [cidade polo do curso de Letras], um BOM DIA com o eco e resplendor das serras...", separada por uma linha pontilhada, foi postada após a apresentação da semana.

Começaremos a nossa análise com o seguinte trecho da consígnia: "Queridos alunos!!! Bom dia!!! Estamos iniciando a nossa $5^{\text {a }}$ semana de aula...", ou seja, a apresentação da semana. Nesse trecho, percebemos que a escolha do adjetivo "queridos" e a saudação "Bom dia" sugerem que o professor Lucas procura estabelecer uma relação mais próxima com os/as alunos/as. Há o registro explícito de uma suposta afetividade que institui para o/a aluno/a um determinado papel em relação ao esse professor. Ele não é mais um/a aluno/a, mas um/a aluno/a querido/a. Já a sequência de três exclamações que seguem (queridos alunos!!!) procura estabelecer certo tom de "animação" ao primeiro contato do/a aluno/a com a tela do computador. Podemos afirmar que essas marcas de interlocução não são comumente encontradas nos contextos interacionais de sala de aula (seja nos registros escritos, seja oralmente nas relações estabelecidas presencialmente) ${ }^{17}$ e podem revelar, de certa forma, deslocamentos identitários desses construtos sujeitos (professor/a e aluno/a) na contemporaneidade e uma constituição ética discursiva aportada numa relação mais próxima entre papeis professor/a aluno/a. Segundo Hall (2006, p. 88):

\begin{abstract}
Em toda parte, estão surgindo identidades culturais que não são fixas, mas que estão suspensas, em transição, entre diferentes posições; que retiram seus recursos, ao mesmo tempo, de diferentes complicados cruzamentos e misturas culturais que são cada vez mais comuns num mundo globalizado.
\end{abstract}

No parágrafo seguinte, onde o professor registrou: "Estamos iniciando a nossa quinta semana...", ele preferiu as reticências ao ponto final. Essa troca de pontuação nos permite interpretar uma lógica discursiva de suspensão de ideias

\footnotetext{
17 Não se trata de comparar as modalidades de ensino, nem de generalizar práticas tão diversas de professores/as. Entendemos que, a depender do contexto educacional, da formação do professor e da integração de um ensino reflexivo à prática docente, podemos sim encontrar esse tipo de abordagem pedagógica.
} 
para a complementação do sentido do outro. O movimento discursivo ético, marcado pelo uso das reticências, sugere uma complementação do aspecto de se evidenciar um diálogo através da pergunta "O que faremos?". Essa pergunta apresenta uma estrutura da comunicação face a face, pois, ao invés de construir um parágrafo com uma sequência textual tipológica descritiva, o docente utiliza o esquema de pergunta e resposta, processo visto como uma antecipação de discursos por considerar uma suposta voz de seu/sua interlocutor/a. A identidade docente, nesse caso, é constituída pela pluralidade discursiva. O docente em questão assume um saber construído junto a seus/as alunos/as. Professor Lucas não é o detentor do saber que orienta como esse saber vai ser consumido pelos/as discentes, ele é o operário do saber, num exercício onde todos trabalham (Bom trabalho para todos nós!!!). Observamos que, a partir dessas estratégias do dizer, é possível refletir sobre os indícios identitários, pois a palavra como signo ético-ideológico diz muito do sujeito quando esse a emprega.

Dando continuidade, observamos também que o professor utiliza expressões de estímulos como: "Vamos à luta!!!!" e "Bom trabalho para todos nós!!!", novamente com o uso das exclamações. O professor coloca-se lado a lado nas atividades que serão desenvolvidas: estamos iniciando, faremos, discutiremos, entraremos na produção.

A própria proposta de trabalho do objeto de ensino culmina com um concurso de contos que subtende não apenas a prática individualizada da atividade, mas uma integração coletiva de ação. Os/as alunos/as não apenas produzirão um conto, eles/as "entrarão na produção para a montagem de uma brochura e concorrência num concurso". A constituição identitária do docente é ratificada na coletividade também pela proposta de ensino. Vejamos o trecho a que nos referimos abaixo:

\section{Trecho 3:}

E, finalmente, entraremos na produção de um conto para montagem de uma brochura e concorrência num concurso de contos.

Vamos à luta!!! Bom trabalho para todos nós!!!

Para a realização das ações propostas por ele, é interessante perceber que, ao invés de desejar esse bom trabalho para os/as alunos/as, como é de 
costume para a maior parte dos/as professores/as, ele também se inclui nesse contexto, numa forma de interação com o/a aluno/a. Por esse viés, entendemos que o discurso ético pode se estabelecer em qualquer uma dessas três instâncias: no nível da informação, no da contextualização e no da implicação prática do conhecimento aos outros conhecimentos. (SOUTO MAIOR, 2018, p. 147). E é nessa terceira dimensão que as práticas desse professor se encontram. Essa inclusão do outro, percebida na escolha da pessoa "nós" para os verbos das ações escolhidas para a semana: "faremos", "discutiremos", "entraremos", reforça o entendimento de que a

interação da palavra em função do interlocutor tem uma importância muito grande. Na realidade, toda palavra comporta duas faces. Ela é determinada pelo fato de que procede de alguém, como pelo fato de que se dirige para alguém" (VOLÓCHINOV, 2014, p. 117).

Outro aspecto importante que destacamos está na primeira parte do texto, quando esse se inicia com a saudação e vocativo utilizados pelo professor: "Pessoal de [tal lugar] ${ }^{18}$, um BOM DIA com o eco e resplendor das serras, neblinas e vegetação dessa região aí!!! rsrsrsrsrs!!!". A escolha do vocativo "Pessoal de [tal lugar]", a expressão "BOM DIA" em caixa alta, seguida da palavra eco e da característica da cidade "resplendor das serras, neblinas e vegetação", sugerindo um bom dia ecoando nas serras, numa imagem poética e, ao mesmo tempo, uma linguagem descontraída, ao utilizar a onomatopeia "rsrsrsrsrs!", podem demonstrar novamente a intenção de aproximação e a valoração desse/a aluno/a que não é mais apenas um/a aluno/a, mas um/a aluno/a de um determinado lugar. O professor Lucas, ao apresentar características do lugar em que ocorre o curso, marca novamente sua estratégia de aproximação. Essa estratégia do dizer, com o uso de metáforas e adjetivações, registra a tentativa de ênfase numa relação mais aproximada para com o aluno.

Ainda nessa primeira parte do texto, observamos que o docente apresenta uma sequência de procedimentos necessários para a realização adequada do trabalho.

\footnotetext{
${ }^{18}$ Suprimimos a cidade a que se referiu o professor.
} 


\section{Trecho 4:}

Para enviar as atividades use a ferramenta: "Tarefa". Quando abrir, clique no "link": "Acrescentar item", ok?

Abraços carinhosos e tenham BONS DIAS!!!

Lucas, tutor 1 e tutor 2

Há a presença de verbos no imperativo "clique" e "use" com a intenção apelativa da linguagem de chamar a atenção dos alunos para esses procedimentos. Além disso, o uso da expressão "ok?", típica de um diálogo mais informal. O adjetivo "carinhosos", referente a "abraços", a utilização da caixa alta na expressão "BONS DIAS" e a repetição das interjeições apresentam novamente o desejo de aproximação entre professor e aluno, pela descontração que demonstra.

Mesmo estando numa separação espaço-temporal, essas estratégias vão estabelecendo novas representações identitárias que aproximam de certa forma, não no espaço-tempo, mas na perspectiva da afetividade. Esse estímulo na relação, que pode ser aceita ou não, estranhada ou afirmada por seus/suas alunos/as, vai dialogando com a constituição identitária estabelecida por papéis previamente estipulados (distanciamento e formalidade) e por papéis que vão se delineando com os novos contextos da modalidade.

Se fizermos uma comparação entre as estratégias do dizer, utilizadas pelos dois professores, Ingrid e Lucas, podemos observar que ambos desejam estabelecer uma relação dialógica com seus/suas alunos/as. A professora Ingrid marcou sua intenção discursiva com um tom de formalidade e o caráter acadêmico ${ }^{19}$. Já o professor Lucas utilizou uma linguagem mais descontraída, próxima a comunicação face a face. As estratégias utilizadas por ambos, embora diferentes no tocante ao caráter pessoal, assemelham-se no propósito de contribuir para a aprendizagem do aluno, um dos principais objetivos de qualquer modalidade de ensino.

19 Podemos reconhecer que não se trata de uma orientação geral, no campo da educação a distância, o emprego da formalidade. Mas nosso propósito não foi qualificar possíveis implicações da abordagem metodológica, portanto apenas registramos que outros aspectos poderiam ser pesquisados sobre a prática descrita. 
Dessa forma, podemos dizer que as marcas linguístico-discursivas das consígnias analisadas apresentam marcas identitárias próprias do/a professor/a em estudo, além das marcas de identidade do docente mais contemporâneas:

- Tenta através de uma linguagem formal e informal estabelecer relação dialógica com o aluno.

- $\quad$ Preocupa-se com o desenvolvimento e processo das atividades propostas ao apresentar os procedimentos corretos para a realização das ações, numa postura de compromisso com o aluno e organização didática e pedagógica.

- Utiliza formas variadas de ferramentas para auxiliar o processo de ensinoaprendizagem.

A seguir, apresentaremos nossas considerações finais.

\section{Considerações finais}

A análise das práticas linguístico-discursivas do gênero consígnia aponta para um gênero híbrido que se adequa à realidade de educação a distância, mediada por um ambiente virtual onde a linguagem escrita é o principal meio de interação entre professor/a e aluno/a, objetivando o desenvolvimento do processo de ensino-aprendizagem numa dimensão ético-discursiva contemporânea. Esse hibridismo é construído em cada ambiente, na medida em que a aprendizagem é facilitada através de ferramentas virtuais e a linguagem utilizada se adequa a cada ferramenta e à prática de atuação de cada professor/a.

Observamos, com o estudo, que esse gênero, organizado com saudações e orientações, sinaliza para a construção de diferentes relações sociais entre docente-discentes, revelando: a) estruturalmente: marcas linguístico-discursivas num continnum, entre a formalidade e a informalidade; b) interacional e discursivamente: a ratificação ou não de uma postura mais próxima e menos institucionalizada entre professor/a-aluno/a pela dimensão ético-discursiva; c) Identitariamente: a construção de subjetividade mais simétrica ou não em 
relação ao aluno (com a promoção de aproximações e distanciamentos entre eles). Entendemos que essas diferenças revelam fragmentações identitárias próprias da busca de uma reavaliação do que o ambiente demanda para os/as profissionais.

Além dessas características, as consígnias também podem ser vistas por se constituírem como a voz do/a docente no ambiente virtual, como espaço próprio para a avaliação do resultado dessas posturas do/a professor/a em EaD, tais como: profissional colaborativo/a, dinâmico/a, comprometido/a com o processo ensino-aprendizagem, que usa a linguagem mais formal e/ou mais informal para estabelecer uma relação dialógica com o/a aluno/a. Tais características se constroem e se reconstroem a partir de um contexto fluido, instável da contemporaneidade.

\section{Referências}

ANDRÉ, Marli Eliza Dalmazo Afonso de. Etnografia da prática escolar. Campinas: Papirus, 1995.

BAUMAN, Zygmunt. O mal-estar da pós-modernidade. Tradução: Mauro Gama e Cláudia Martineli Gama. Rio de Janeiro: Jorge Zahar Editor, 1998.

BAUMAN, Zygmunt. Modernidade líquida. Tradução: Plínio Dentzien. Rio de Janeiro: Jorge Zahar Ed, 2001.

BAUMAN, Zygmunt. Identidade: entrevista a Benedetto Vecchi. Tradução: Carlos Alberto Medeiros. Rio de Janeiro: Zahar, 2005.

BAUMAN, Zygmunt. Globalização: as consequências humanas. Tradução: Marcus Penchel. Rio de Janeiro: Jorge Zahar Ed., 1999.

BELLONI, Maria Luiza. Educação à distância. 5. ed. São Paulo: Autores Associados, 2008.

BRASIL. Ministério da Educação. Portal do MEC. Decreto № 5.622. Brasília, 2005. Disponível em:

http://portal.mec.gov.br/sesu/arquivos/pdf/portarias/dec5.622.pdf . Acesso em: 08 ago. 2018.

CASTELLS, Manuel. O poder da identidade. São Paulo: Paz e Terra, 2010.

CELANI, Maria A.; MAGALHÃES, M. C. C. Representações de professores de inglês como língua estrangeira sobre suas identidades profissionais: uma 
proposta de reconstrução. In: MOITA LOPES, Luiz Paulo; BASTOS, Liliana C. (org.). Identidades: recortes multi e interdisciplinares. Campinas: Mercado de Letras, 2002.

CORACINI, Maria J. R. F. Subjetividade e identidade do professor de português. Trabalhos em Linguística Aplicada, Campinas, v. 36, p. 147-158, jul./dez. 2002. Disponível em:

http://revistas.iel.unicamp.br/index.php/tla/article/view/2509/4703. Acesso em: 25 fev. 2016.

CORACINI, Maria J. R. F. O discurso da linguística aplicada e a questão da identidade: entre a modernidade e a pós-modernidade. In: CORACINI Maria J. R. F.; BERTOLDO, E. S. (org.). O desejo da teoria e a contingência da prática: discursos sobre/na sala de aula. Campinas: Mercado de Letras, 2003.

CORACINI, Maria J. R. F. Interação e sala de aula. Revista Calidoscópio, v. 3, set./dez. 2005.

FABRÍCIO, Branca Falabela; MOITA LOPES, Luiz Paulo da. Discursos e vertigens: identidades em xeque em narrativas contemporâneas. Revista Veredas, Juiz de Fora, v. 6, n. 2 p. 11-29, jul./dez. 2002.

GIDDENS, A. As consequências da modernidade. São Paulo: Editora UNESP, 1991.

HALL, Stuart. A identidade cultural na pós-modernidade. 11. ed. Rio de Janeiro: DP\&A, 2006.

HALL, Stuart. Quem precisa de identidade? In: SILVA, Thomaz Tadeu da. Identidade e diferença: a perspectiva dos estudos culturais. 3. ed. Petrópolis, RJ: Vozes, 2004.

LUDKE, Menga; ANDRÉ, Marli E. D. A. Pesquisa em educação: abordagens qualitativas. São Paulo: EPU, 1986.

MARCELO, Carlos. A identidade docente: constantes e desafios. Revista Brasileira de Pesquisa sobre Formação Docente, Belo Horizonte, v. 1, n. 1, p.109-131, 2009.

MOITA LOPES, Luiz Paulo da. Identidades fragmentadas: a construção da raça, gênero e sexualidade em sala de aula. Campinas: Mercado das Letras, 2002.

MOITA LOPES, Luiz Paulo da (org.). Por uma linguística aplicada indisciplinar. São Paulo: Parábola Editorial, 2006.

PIMENTA, Selma Garrido Pimenta. Formação de professores: identidade e saberes da docência. In: PIMENTA, Selma Garrido Pimenta. Saberes pedagógicos e atividade docente. 8. ed. São Paulo: Cortez, 2012. 
RODRIGUES, Rosângela Hammes. Os gêneros do discurso na perspectiva dialógica da linguagem: a abordagem de Bakhtin. In: MEURER, J. L.; BONINI, A.; MOTTA-ROTH, D. (org.). Gêneros: teorias, métodos, debates. São Paulo: Parábola Editorial, 2005.

SANTOS, Boaventura de Sousa. Modernidade, identidade e a cultura de fronteira. Tempo social; Rev. Sociol. USP, São Paulo, v. 5, n. 1-2, p. 31-52, 1993.

SOUTO MAIOR, Rita de Cássia. As constituições de ethos e os discursos envolventes no ensino de língua portuguesa em contexto de pesquisa-ação. Tese (Doutorado em Linguística) - Faculdade de Letras, Universidade Federal de Alagoas, Maceió, 2009.

SOUTO MAIOR, Rita de Cássia. Pensamento bakhtiniano nos estudos da linguagem: a ação do pesquisador como ato responsável. Polifonia, Cuiabá, v. 20, n. 27, p. 31-53, jan./jun. 2013.

SOUTO MAIOR, Rita de Cássia. Os saberes docentes e a constituição de ethos no PIBID/LETRAS: a construção de uma ética discursiva. In: FIGUEIREDO, Francisco José Quaresma; SIMÕES, Darcília. Contribuições da linguística aplicada para a educação básica. Campinas: Pontes Editores, 2018.

TRIVIÑOS, Augusto Nibaldo Silva. Introdução à pesquisa em ciências sociais: a pesquisa qualitativa em educação. São Paulo: Atlas, 1987.

VOLÓCHINOV, Valentin. Marxismo e filosofia da linguagem. São Paulo: Hucitec, 2014.

YIN, Robert K. Estudo de caso: planejamento e métodos. Tradução: Daniel Grassi. 3. ed. Porto Alegre: Bookman, 2005. 